\title{
Computational Studies on the Sulfur Dioxide Absorption by Organic Lewis Bases
}

\author{
Jae-Goo Shim, Young H. Jhon, ${ }^{\leftarrow}$ Jun-Han Kim, Kyung-Ryong Jang, and Jaheon Kim ${ }^{\dagger+*}$
Global Environment Research Grotp. Enwironment \& Strichtre Laboratory, Korea Electric Power Research Institute. Daejeon 305-380, Korea
${ }^{\dagger}$ Department of Chemisty and CAMDRC', Soongsil University, Seoul 156-743, Korea. "E-mail: jaheonialssuac.kr Received June 25, 2007

Key Words : Sulfur dioxide, Amine, Absorption, Lewis acid-base complex, DFT, Ab initio

The flue gas emitted by burning of fossil fuels is a significant source of the atmospheric sultur dioxide $\left(\mathrm{SO}_{2}\right)$. As $\mathrm{SO}_{2}$ can produce eventually sulfuric acid after oxidation and reaction with water, it is considered as one of the main sources causing acid rain. To prevent the environmentally harmful gas from exposing to atmosphere, the flue gas desulfurization (FGD) processes such as limestone-scrubbing and chemical absorption are requested in the fire power plant. Currently, among many sorbents limestone $\left(\mathrm{CaCO}_{3}\right)$ is widely used for a scrubbing process which utilizes the chemical reaction between $\mathrm{CaCO}_{3}$ and $\mathrm{SO}_{2}$ to give solid $\mathrm{CaSO}_{\text {.. }}$ As this process gives a large amount of solid waste cakes as by-products as well, the new absorption methods using organic solvents as $\mathrm{SO}_{2}$-removal agents have been explored because the absorbing agents can be regenerated repeatedly. ${ }^{1-5}$

The $\mathrm{SO}_{2}$ removal method by organic solvents is generally composed of two steps: 1) a fixation of $\mathrm{SO}_{2}$ from the flue gas by the formation of a absorbent- $\mathrm{SO}_{2}$ complex. and 2) thermal regeneration of absorbing agents and $\mathrm{SO}_{2}$ stripping at the same time. The working process looks similar to that of an amine- $\mathrm{CO}_{2}$ reaction which is an important $\mathrm{CO}_{2}$ removal method from the flue gas. However, in the case of the $\mathrm{SO}_{2}$ absorption and stripping, Lewis acid-base reactions involving dative bonds as shown in Scheme 1 happen while amines react with $\mathrm{CO}_{2}$ to produce carbamates via covalent bonds. ${ }^{4,6}$ This difference in the reaction mechanism was experimentally verified that Lewis basicity parameterized by Gutmann donor number ( $D_{N}$ ) was related to the reactivity of the $\mathrm{SO}_{2}$ absorption while it did not for the $\mathrm{CO}_{2}$ case. ${ }^{+}$

Various sulfur dioxide complexes at molecular level have been extensively studied by Kuczkowski and coworkers. ${ }^{7}-10$ They classified sulfur dioxide complexes according to the types of interactions into charge-transfer complexes, van der Waals complexes, and hydrogen-bonded complexes. ${ }^{10} \mathrm{Gas}$ phase complexes were investigated by microwave spectroscopy and ab initio calculations, and solid state structures by
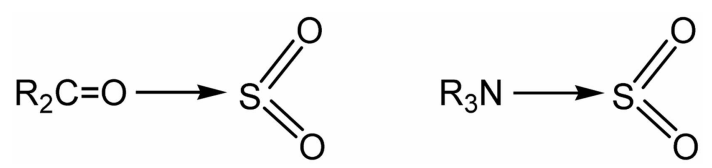

Scheme I. Representalive sul lur dioxide complexes formed $x$ ith a dative boind, O-S or N-S bonding.
X-ray crystallography. Leopold $e$ al. also have extensively studied "partially formed bonds" in Lewis acid-base complexes containing $\mathrm{BF}_{3}$ and $\mathrm{SO}_{\text {s }}$ as Lewis acids. "The Lewis acid-base complexes are actually same as the charge-transfer complexes classified by Kuczkowski and coworkers. Interestingly, the bond lengths of the partial dative bonds in the gas phase become significantly shorter in solid, and turn into nearly full dative bonds. This phenomenon has been attributed to more enhanced dipole moment interactions in
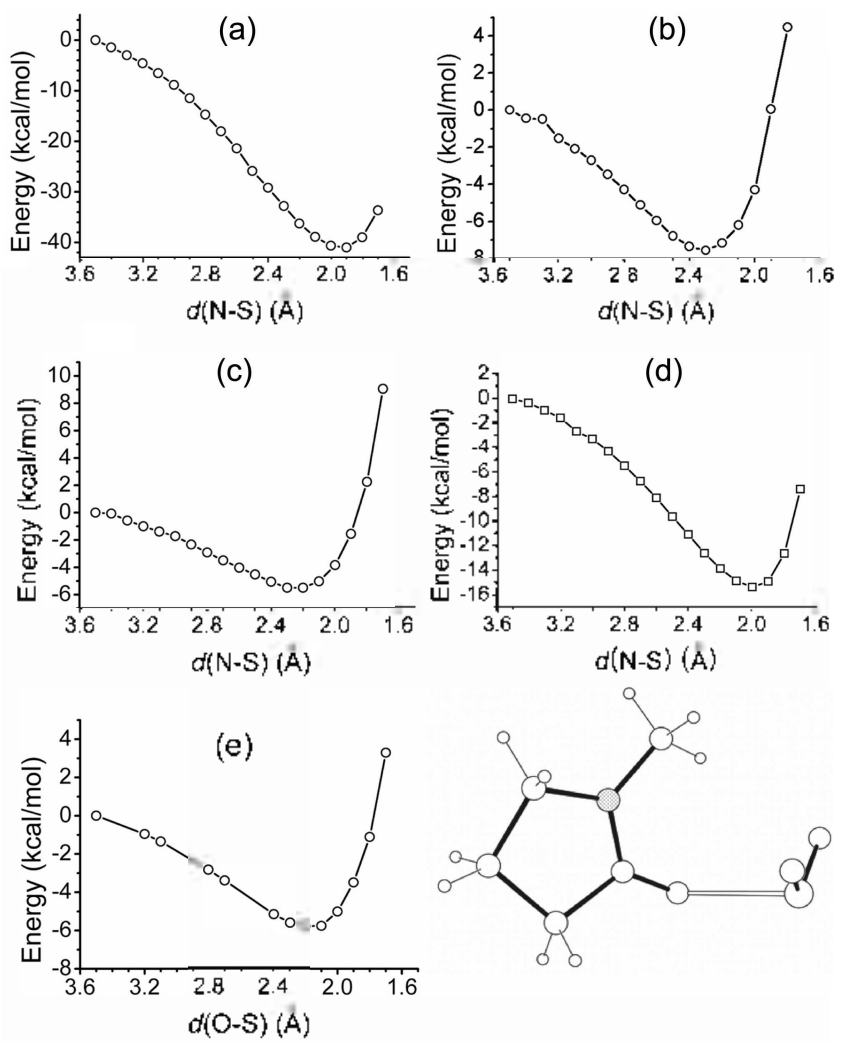

Figure 1. Energy profiles of the reactions hetween amine molecules and $\mathrm{SO}_{2}$ in aqueous environments are plotted with respect to the constraint reaction coordinates. III calculations in gats phases were used to optimize each structure, and then each energy value was determined by a higher level DFT calculation and applying a PCM solvation model (See Experimental Section). Plots for (a) $\mathrm{IMA}-\mathrm{SO}_{2}$, (b) $\mathrm{II} \mathrm{A}-\mathrm{SO}_{2}$ (c) $\mathrm{Ml} \mathrm{A}-\mathrm{SO}_{2}$, (d) pyridine- $\mathrm{SO}_{2}$. and (c) $\triangle \mathrm{MP}^{\mathrm{S}}-\mathrm{SO}_{2}$. The energy-minimum structure of $\mathrm{NMP}-\mathrm{SO}_{2}$ is showin with a ball-and-stick model where a dotted ball is $\mathrm{N}$ atom, and the open bond indicates an $\mathrm{O}{ }^{\cdots} \mathrm{S}$ dative bond. 
the condensed phase. However, it is noticeable that TMAand DMA-SO2 $($ TMA = trimethylamine, DMA = dimethylaine) complexes having 2.046(4), and 2.003 (12) $\AA$ for $d(\mathrm{~N}$ S)s in solid, respectively, are only about $0.25 \AA$ contraction from those in gas phases. ${ }^{7.11}$

Considering that the $\mathrm{SO}_{2}$ complexes have been studied for a long time, it is our surprise that there have been yet no theoretical investigations on the $\mathrm{SO}_{2}$ complexes by the viewpoint of the $\mathrm{SO}_{2}$ removal. Only chemical engineers have been interested in this issue, and studied the $\mathrm{SO}_{2}$ removal process experimentally. ${ }^{1-5}$ In this regard we have conducted quantum mechanical computations to trace the reaction between amines and $\mathrm{SO}_{2}$, and to calculate binding energies of the stable Lewis acid-base complexes in both a gas phase and an aqueous environment. Lewis bases dealt with in this work were trimethylamine (TMA), triethylamine (IEA), monoethanolamine (MEA), pyridine, and methylpyrolidone (NMP), where NMP' did not form an $\mathrm{SO}_{2}$ complex via an N-S bond but reacts with $\mathrm{SO}_{2}$ by forming a $\mathrm{O}$ (carbonyl)-S bond (Figure le).

The constraint has been applied to the inter-atomic distances between each $\mathrm{N}$ atom in TMA. TEA. MEA, and pyridine and the $\mathrm{S}$ atom of $\mathrm{SO}_{2}$. For the case of TMA, the distance started from the value close to a sum of van der Waals radii. $3.35 \AA$ for $\mathrm{N}$ and $\mathrm{S}$ atoms, which was gradually reduced by $0.1 \AA$ to $1.7 \AA$, near the sum of the covalent radii, $1.78 \AA$. The energy-minimum was obtained at $1.90 \AA$ with a gradual stabilization after which the energy increased abruptly (Figure la). The overall energy profile indicates that the absorption reaction for TMA is a one-step reaction forming N-S bonding with no transition state, which was also observed for the previous reports on TMA-SO ${ }_{2}{ }^{7}$ and $\mathrm{NH}_{3}-\mathrm{BF}_{3}{ }^{1]}$ Similar trends lave been observed for the other amines, TEA, MEA and pyridine with the optimized N-S distances of 2-2.3 $\AA$ (Figures Ib, lc and Id). The NMP-SO complex has an energy-minimum at an $\mathrm{O}-\mathrm{S}$ distance of $\sim 2,2$ $\AA$ (Figure le).
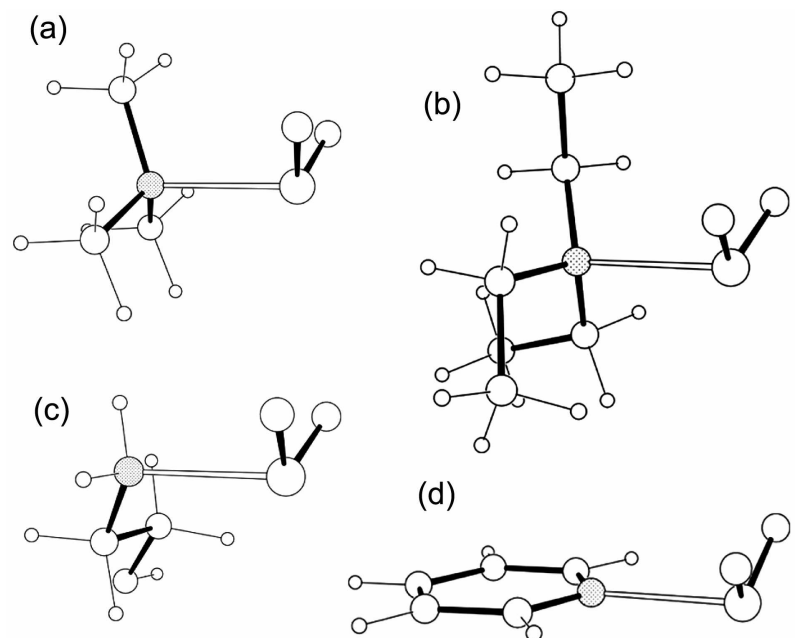

(d)

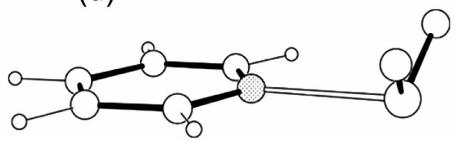

Figure 2. Final optimized structures of the $\mathrm{SO}_{2}$-complexes with Lewis bases, (a) TMA. (b) TEA, (c) MFA, and (d) pyridine. Dotted balls are $\mathrm{N}$ atoms, and small balls are II atoms. I ative bonds are drawn with open sticks which link $X$ and $S$ atoms.
The energy-minimum structures found during studies on the reaction pathways were further optimized by DFI$\mathrm{B} 3 \mathrm{LY} / 6-311++\mathrm{G}(\mathrm{d}, \mathrm{p})$ computations. As the additional calculations were done for the gas phase complexes, parallel DFl studies with PCM (l'olarized Continuun Model) were also carried out to check the variations of the structural and energetic values in aqueous environments. The final structures adjusted by PCM models are drawn in Figure 2, the final geometric values and binding energies corresponding to gas phase $(g a s)$ or solvated ( $s o l)$ structures are listed in Table $\mathrm{I}$, and the definition of the geometric parameters are depicted in Figure 3.

Both distances of N-S and $\mathrm{O}-\mathrm{S}$ bonds in a gas phase or with a solvation model range between the sum of covalent radii $(\mathrm{N}-\mathrm{S}=1.78 \AA ; \mathrm{O}-\mathrm{S}=1.78 \AA)$ and the sum of van der Waals (vdW) radii ${ }^{12}(\mathrm{~N} \cdots \mathrm{S}=3.35 \AA ; \mathrm{O} \cdot \mathrm{S}=3.32 \AA$ ), which is indicative of the "partially formed bonds"." The N-S distances of IMA- and pyridine- $\mathrm{SO}_{2}$ complexes are wellmatched to the experimental values in gas phases (2.26, and $2.61 \AA$. respectively). ${ }^{7.10}$ These values become smaller by about $0.29 \AA$ with maintaining overall conformations when PCM models were applied. The calculated binding energy of the TMA-SO 2 complex $(-9.07 \mathrm{kcal} / \mathrm{mol})$ in a gas phase is very close to the experimental value $(-9.1 \mathrm{kcal} / \mathrm{mol}){ }^{7.13} \mathrm{It}$ becomes larger by $1.0 \mathrm{kcal} / \mathrm{mol}$ when a PCM model was applied. On the contrary of the TMA- $\mathrm{SO}_{2}$ case, the binding energies for other amines become smaller. Others reported previously the binding energies obtained by various levels of $a b$ inito calculations for a pyridine- $\mathrm{SO}_{2}$ complex. ${ }^{10} \mathrm{How}-$ ever, the values are not sufficient for the quantitative description because the calculated values for $\mathrm{TMA}-\mathrm{SO}_{2}$ using same computational levels were significantly deviated from the experimental value. The bond distances, $d(\mathrm{~N}-\mathrm{S}) \mathrm{s}$ obtained by PCM models lie between those in gas and in

Table I. Binding energy, geometric parameters. and basicity parameters of various $\mathrm{SO}_{2}$-amine complexes

\begin{tabular}{|c|c|c|c|c|c|}
\hline \multicolumn{2}{|c|}{ Contents } & \multirow{2}{*}{$\begin{array}{r}\text { TMA } \\
-9.07\end{array}$} & \multirow{2}{*}{$\begin{array}{r}\text { TEA } \\
-7.08\end{array}$} & \multirow{2}{*}{$\begin{array}{c}\text { MEA } \\
-5.69\end{array}$} & \multirow{2}{*}{$\begin{array}{c}\text { pyridino } \\
-6.14\end{array}$} \\
\hline Binding & $g q s$ & & & & \\
\hline $\begin{array}{c}\text { energy } \\
\text { (kcalimol) }\end{array}$ & sol & -10.05 & -6.80 & -5.01 & -4.42 \\
\hline \multirow{2}{*}{$d(N-S)(A)$} & $g q s$ & 2.422 & 2.461 & 2.570 & 2.536 \\
\hline & sol & 2.188 & 2.279 & 2.178 & 2.195 \\
\hline \multirow{2}{*}{$\alpha\left({ }^{\circ}\right)$} & gas: & 176.47 & 174.01 & $123.62^{\prime \prime}$ & 176.37 \\
\hline & sol & 178.82 & 174.53 & $117.28^{: t}$ & 178.57 \\
\hline \multirow{2}{*}{$\beta\left(0^{\circ}\right)$} & $g q s$ & 101.71 & 104.63 & 100.32 & 100.53 \\
\hline & sol & 106.35 & 107.94 & 105.33 & 104.16 \\
\hline \multirow{2}{*}{$\gamma\left({ }^{\circ}\right)$} & gas & -0.32 & 29.84 & $16.22^{h}$ & 87.70 \\
\hline & sol & -1.33 & 27.68 & $18.91^{h}$ & 90.72 \\
\hline \multicolumn{2}{|c|}{$D_{s}($ kcalimol $)$} & $60.0^{14}$ & $61.0^{15}$ & $\mathrm{NA}$ & $33.1^{1+}$ \\
\hline \multicolumn{2}{|c|}{$p K_{a}$ at $25^{\circ} \mathrm{C}$} & $9.9^{10}$ & $10.75^{17}$ & $9.51^{18}$ & $5.21^{17}$ \\
\hline
\end{tabular}

"MГA has a pseudo $C_{3}$ axis. and the direction of the electron lone pair at $\mathrm{N}$ is not coincident with the axis. "A torsion angle delined by $\mathrm{H}-\mathrm{N}-\mathrm{S}-\mathrm{X}$ (See Higures 2 and 3 ). 
(a)

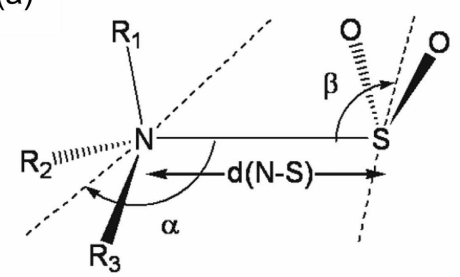

(b)
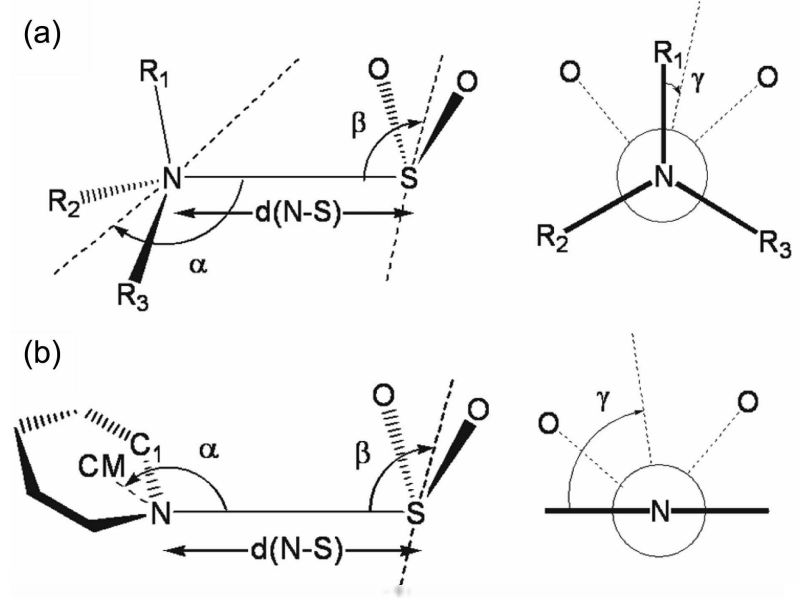

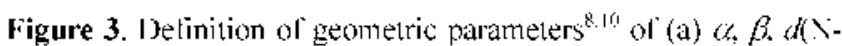
S), and $\gamma$ of aliphatic amines. and (b) those of pyridine. The parancter $\alpha$ or $\beta$ is the angle between the $C_{s}$ axis of amine or the $\mathrm{C}_{2}$ axis of $\mathrm{SO}_{2}$, and $\mathrm{N}-\mathrm{S}$ bond, respectively. The parameter $\gamma$ is the torsion angle $\mathrm{R}_{1}-\mathrm{N}-\mathrm{S}-\mathrm{X}$. I fere $\mathrm{X}$ is an arbitrary point on the $\mathrm{C}_{2}$ avis. In the case of pyridince. the parameters. $\alpha$ and $y$ are the $C \mathrm{M}-\mathrm{N}-\mathrm{S}$ angle and the torsion angle. $\mathrm{C}_{1}-\mathrm{X}-\mathrm{S}-\mathrm{X}$. respectively. CM represents the center of mass of the aromatic ring.

solid phases, which implies that the calculated binding energies for TEA, MEA, and pyridine- $\mathrm{SO}_{2} \mathrm{~S}$ are reasonable enough to describe stabilities in aqueous environment although the variation tendency is obverse to that of TMA$\mathrm{SO}_{2}$.

As the strength of the Lewis bacisity increases, stronger binding energies and shorter $d(\mathrm{~N}-\mathrm{S})$ values would be expected. As shown in 'lable I, there is a general correlation between the basicity and binding energy, however bond lengths do not follow this trend. For example, TMA. TEA, and MEA are more basic - they have larger $D_{\vee}$ numbers and $p K_{\mathrm{a}}$ values- and have larger binding energies than pyridine, but the $d(\mathrm{~N}-\mathrm{S})$ length of IEA is not shorter than that of pyridine. A plausible reason for the unexpected observation may be ascribed to the presence of the bulky ethyl groups in TEA which makes steric hindrance come into effect. Supporting evidences can be found in the geometric parameters, $\alpha$ and $\beta$ (Figure 3 ). When there is steric hindrance two contacting groups would tend to be separated from each other, which will result in smaller $\alpha$, and larger $\beta$ values. In pyridine- $\mathrm{SO}_{2}$ complex, $\mathrm{SO}_{2}$ moiety does not feel a significant steric hindrance because it is almost vertical to the molecular plane of the pyridine ring with $\beta=104.16^{\circ}$ (lable 1). For the MEA-SO2 complex, as two hydrogen atoms bound to an $\mathrm{N}$ atom face $\mathrm{SO}_{2}$ moiety, it is easily expected that the magnitude of the steric hindrance is much smaller than those in TMA and TEA. Based on these speculation and observation. we can say that the overall steric hindrance increases with the increasing order, pyridine $<$ MEA < IMA < T'EA. In short, the binding energy is correlated to the basicity or $\mathrm{D}_{\mathrm{N}}$, and the steric effect diminishes the binding energy somewhat with increased $d(\mathrm{~N}-\mathrm{S})$ distances.

In summary, this work shows by computational appro- aches that various absorption agents having primary, tertiary, and aromatic amines are able to form stable Lewis acid-base complexes with $\mathrm{SO}_{2}$ without forming particular transition states. The dative bond lengths indicate the all the I.ewis acid-base complexes in this study are partially bound complexes. The binding energies calculated in aqueous environments are increased by $10.8 \%$ for TMA- $\mathrm{SO}_{2}$, and decreased by $4.0 \%, 12.0 \%$, and $28.0 \%$ for TEA-, MEA-, and pyridine- $\mathrm{SO}_{2} \mathrm{~s}$, respectively, If the binding energy of $\mathrm{H}_{2} \mathrm{O}$ $\mathrm{SO}_{2}$ is similar to that of DME- $-\mathrm{SO}_{2}(3.6 \mathrm{kcal} / \mathrm{mol}: \mathrm{DMF}=$ dimethylether)." it is likely that they have a chance to form the complexes, and can be used in absorption of $\mathrm{SO}_{2}$ as aqueous solvents. Finally, a relatively good correlation has been observed between the strengths of binding energies and the basicities of the amines.

\section{Computational Section}

To find out the reaction pathways, geometric parameters intimately involved in the reaction, that is. $\mathrm{N}-\mathrm{S}$, and $\mathrm{O}-\mathrm{S}$ distances have been chosen as pseudo reaction coordinates. A series of quantum mechanical calculations were run by fixing the inter-atomic distances at each step, and the structures of the complexes was optimized. ${ }^{10}$ Ab initio ( $\mathrm{HF}$ ) in gas phase and $\mathrm{DF}^{\prime} \mathrm{J}$ in solvation phase are used for the geometry optimization and energy calculation, respectively. $\mathrm{HF}$ method adopted basis set of $6-3 \mathrm{l}+\mathrm{G}(\mathrm{d}, \mathrm{p})$ for $\mathrm{C} . \mathrm{H}, \mathrm{N}$, and $\mathrm{O}$ atoms, and $6-31+\mathrm{G}(2 \mathrm{~d})$ for $\mathrm{S}$ atom, while DF" $\mathrm{C}$ used B3LYP functional with $6-311++\mathrm{G}(\mathrm{d} . \mathrm{p})$ basis set for $\mathrm{C}, \mathrm{H}, \mathrm{N}$. and $\mathrm{O}$ atoms, and $6-311++\mathrm{G}(2 \mathrm{~d})$ for $\mathrm{S}$ atom. The used solvation model for an aqueous solution was PCM (Polarized Continuum Model) developed by Tomasi and coworkers. ${ }^{20}$ To define the cavity for a solute, Bondi radii'? were adopted. For the energy calculation, zero potential energy ( $\angle P \mathrm{P} E)$ was also considered

The binding energy (B.E.) of a $\mathrm{SO}_{2}$-amine complex was defined as,

$$
\text { B.E. - } E\left(\mathrm{SO}_{2} \text {-amine complex }\right) \quad E\left(\mathrm{SO}_{2}\right) \quad E \text { (amine) }
$$

The each energy term is corresponding to an optimized $\mathrm{SO}_{2}$-amine complex. $\mathrm{SO}_{2}$, and amine, respectively. The calculations were performed by the same DF" I methods mentioned above. The basis set superposition error (BSSE) was not corrected because the adapted basis sets in this work are sufficiently large and can relieve the error somewhat. Especially. MEA can have an internal hydrogen bond between the terminal $-\mathrm{OH}$ and $-\mathrm{NH}_{2}$ groups, which may cause a significant BSSE, and may need an application of the counterpoise method. ${ }^{21}$ However, as it is beyond our objectives, it was not considered in this work.

Acknowledgement. This work was supported by the KEMCO (Korea Energy Management Corporation).

\section{References}

1. Gleason. Gi H.: Montclair. N. I.: Loonam A. C. L.S. Patent 
21106453.1940.

2. Heisel. M.: Bellani. A. Gas Sep. Pur. 1991. 5.111.

3. (a) Hass. R. H.: Albertson. W. U.S. Patent 4347227. 1982. (b) Jones, M. B.: Fowler. A. E. U.S. Patent 4530704, 1985. (c) Terybig. D. S: Potter J. L.: Jones, M. B.: Motes. I. M. L.S. Patent 4783327, 1988. (d) Christiansen, S. H.: Chang. D. Crump. D. K. U.S. Patent 5098681. 1992. (e) Chang. D.: Bedell. S. A.: Kirby. L. H. U.S. Patent 5433934. 1995.

4. van Dam. M. H. H.: Lamine. A. S.: Roizard. D.: Lochon. P: Roizard. C. Ind Eng. Chem. Res. 1997.36, 4628-4637.

5. Kermadec, R. D; Lapicque, F: Roizard. D.; Roizard. C. If d. Eng. Chem. Res. 2002. H1. 153-163.

6. Sartori. G. Savage. D. W. Ind. Eng. Chem. Fundam. 1987. 22. $239-249$

7. Oh. J. J.: LaBarge. M. S.: Matos. J.: Kampf. J. W.: Hillig I. K. W. Kuczkiowski. R. L. J. Am. Chem. Soc, 1991. 113. $4732-4738$.

8. Oh. J. J.: Hillig I. K. W: Kuezkowski. R. L. J. Phs. Chem. 1991. $95,7211-7216$

9. Oh. J. J.: Hillig II. K. W.: Kuczkowski. R. L. Inorg. Chem. 1991. $30.4583-3588$
10. Oh. J. I.: Hillig II. K. W.: Kuczkowski. R. L. J. Ant. Chent. Soc. 1991. $113.7480-7484$.

11. Leopold. K. R.: Canagaratna. M.: Phillips. J. A. Acc. Chent. Res. 1997. 30, 57-64.

12. Bondi. A. J. Plns. Chem. 1964, 68, 441-451

13. Grundnes, J.: Christian, S. D. J. Am. Chem Soc. 1968, 90. 2239 2245.

14. Gutmantin. V. The Donot-Acceptor Approach to Holecular Interactionts: Pletum press: New York. U. S. A.. 1978

15. Gojlo. E.: Gampe. T.: Krakowiak, J.: Stangret, J. J. Plys. Chem. At 2007. 111. 1827-1834.

16. Pearson, R. G. J. Am. Chem. Soc. 1986. 108,6109-6114

17. Arnentt. E. M.: Mitchell. E. T.: Murty. I. S. S. R. J. Am. Chent. Soc. 1974. 96. 3875-3876.

18. Perin. D. D. Dissociation Constants of Organic Bases in diqueons Solution; Butterworths: London, U. K., 1965; Supplement, 1972.

19. Young. D. C. Computational Chemistry. A John-Wiley \& Sons. Ine.: 2001

20. Miertus. S.: Scrocco. E.: Tomasi. T. Chem. Phus 1981. 55. 117.

21. Boys. S. F.: Bernardi. F. Hol. Phws. 1970. 19. 553 